GARCÍA, Percy. "El principio del ne bis in ídem material en caso de concurrencia de pena y sanción administrativa".

Polít. crim. Vol. 11, No 21 (Julio 2016), Art. 2, pp. 21-33.

[http://www.politicacriminal.cl/Vol_11/n_21/Vol11N21A2.pdf]

\title{
El principio del ne bis in ídem material en caso de concurrencia de pena y sanción administrativa
}

\section{The ne bis in idem principle in matters pertaining to the concurrence of criminal and administrative sanctions}

\author{
Percy García Cavero \\ Universidad de Piura \\ percy.garcia@udep.pe
}

\begin{abstract}
Resumen
El presente artículo se ocupa de uno de los supuestos problemáticos del ne bis in ídem: la imposición de pena y sanción administrativa a una misma persona por un mismo hecho. El objetivo principal es encontrar el fundamento por el cual la sanción se debe limitar, en estos casos, a una sola sanción. Con dicho objetivo, describe primero cuándo tiene lugar una situación de concurrencia de pena y sanción administrativa, luego se encarga de hacer un recuento de la manera en la que la legislación y la jurisprudencia peruana resuelven esta situación desde la perspectiva del principio del ne bis in ídem, posteriormente entra a analizar los presupuestos para la aplicación del principio del ne bis in ídem (en especial, la llamada identidad de fundamento) y plantea finalmente una propuesta de solución desde la perspectiva de la necesidad de pena.
\end{abstract}

Palabras clave: $\mathrm{Ne}$ bis in ídem, pena y sanción administrativa, principio de proporcionalidad, identidad de fundamento.

\begin{abstract}
This article focuses on one of the most problematic applications of the ne bis in idem legal principle which is the imposition of a criminal sanction and an administrative sanction on the same individual for the same conduct. The main objective of this piece is to find the reason for which in cases like these only one type of sanction should be applied. With this intent, it first describes instances where both sanctions concur and then summarizes the way in which Peruvian legislation and case law have solved them based on the ne bis in idem principle. The article then moves on to analyze the elements needed for a correct application of the principle (specially the so called identity of the fundament) and concludes by proposing a solution based on the necessity of imposing a sanction.
\end{abstract}

Key words: $\mathrm{Ne}$ bis in idem, criminal and administrative sanctions, proportionality principle, Identity of the fundament. 
GARCÍA, Percy. "El principio del ne bis in ídem material en caso de concurrencia de pena y sanción administrativa".

\section{Introducción.}

El principio del ne bis in ídem engloba supuestos tan disímiles que difícilmente puede ser abordado, en toda su amplitud, a partir de un mismo fundamento ${ }^{1}$. La presente contribución no pretende, por ello, ocuparse de los distintos supuestos que son resueltos bajo la sombra de este principio. Su pretensión es mucho más modesta, pues se limita al ne bis in ídem material en caso de concurrencia de pena y sanción administrativa. De esta manera, el tema a tratar queda doblemente acotado. Por un lado, se va a centrar en la prohibición de la punición múltiple, sin abordar, en lo absoluto, la problemática del ne bis in ídem procesal como estándar de clausura de procedimientos sancionatorios ${ }^{2}$. Por otro lado, la punición múltiple no será abordada por concurrencia de sanciones de cualquier tipo, sino solamente la que tiene lugar cuando por un mismo hecho al sujeto se le debe imponer una sanción penal y otra administrativa.

Para alcanzar el objetivo propuesto, se procederá primero a describir cuándo se presenta una situación de concurrencia de pena y sanción administrativa que suscita la duda sobre si resulta legítimo aplicar ambas consecuencias jurídicas. Luego de ello, se hará un recuento de la manera como la legislación y la jurisprudencia nacionales resuelven la situación antes descrita desde la perspectiva del principio del ne bis in ídem, destacando, como colofón de dicha revisión, la poca sintonía que existe entre lo que dice la ley y los criterios de decisión de los tribunales judiciales. Con la finalidad de solventar estos desajustes interpretativos se procederá, después de una exposición sucinta sobre los presupuestos para la aplicación del principio del ne bis in ídem y un análisis específico de la llamada identidad de fundamento, a plantear una propuesta de solución que, si bien está dirigida a remediar un problema de interpretación de la legislación peruana, nada impide que pueda ser discutida también en el marco de otros ordenamientos jurídicos.

\section{La situación de concurrencia de pena y sanción administrativa.}

La situación de concurrencia de pena y sanción administrativa sobre un mismo sujeto por la realización de un mismo hecho es fácilmente reconocible. Ella se presenta cuando la comisión de un delito tiene lugar en ámbitos sometidos a una regulación administrativa primaria que cuenta con normas sancionatorias por incumplimiento de los estándares de actuación establecidos ${ }^{3}$. Si el comportamiento concretamente realizado tiene

\footnotetext{
${ }^{1}$ Vid., así, GARCÍA ALBERO, Ramón, "Non Bis in Ídem" material y concurso de leyes penales, Barcelona: Cedes Editorial S.L., 1995, p. 23 y ss. Lo que hace actualmente más difícil una visión unitaria es la vigencia transnacional que se le asigna al principio del ne bis in ídem, lo que es un tema de especial importancia en la Unión Europea (vid., al respecto, VERVAELE, John, "Ne bis in ídem: ¿un principio transnacional de rango constitucional en la Unión Europea?", InDret 1/2014, pp. 1 y ss.).

${ }^{2}$ Marca claramente la distinción del principio del ne bis in ídem como criterio de adjudicación y como criterio de clausura procesal, MAÑALICH RAFFO, Juan Pablo, "El principio del ne bis in ídem en el Derecho penal chileno", Revista de Estudios de la Justicia, № 15 (2011), p. 140; EL MISMO, "El principio Ne bis in ídem frente a la superposición del derecho penal y el derecho administrativo sancionatorio", Polít. crim. Vol. 9, $\mathrm{N}^{\circ}$ 18 (diciembre de 2014), p. 547. Anteriormente, PÉREZ MANZANO, Mercedes, La prohibición constitucional de incurrir en bis in ídem, Valencia: Tirant lo Blanch, 2002, pp. 57 y s., 67 y ss.

${ }^{3}$ Vid., BAJO, Miguel; BACIGALUPO, Miguel, "Las medidas administrativas y penales de prevención del blanqueo de capitales en el ámbito urbanístico: Límites entre las infracciones administrativas y delito", ADFUAM 12 (2008), p. 15 y ss., aunque críticamente por ir en contra de la división de poderes.
} 
Polít. crim. Vol. 11, № 21 (Julio 2016), Art. 2, pp. 21-33.

[http://www.politicacriminal.cl/Vol_11/n_21/Vol11N21A2.pdf]

simultáneamente una relevancia penal y administrativa en términos de infracción legal, entonces tanto una regulación como la otra reclamarán imponer a su autor la sanción legalmente prevista, por lo que éste será pasible dos consecuencias jurídicas sancionatorias por un mismo hecho.

En cuanto a la regulación administrativa primaria, los estudios especializados ordenan los supuestos en dos grande grupos. Por un lado, están los supuestos en los que la regulación administrativa sectorial se hace sobre la base de una relación de sujeción general de los administrados a la potestad regulatoria de la Administración, como es el caso del tráfico rodado, el sistema tributario, el sistema financiero o el tráfico de productos fiscalizados. Por otro lado, se alude a los supuestos en los que la regulación administrativa se sustenta en una relación de sujeción especial del particular a ciertos organismos estatales u asociativos, tal como se presenta en el caso de los funcionarios públicos, las personas privadas de su libertad en centros penitenciarios o los militares. La primera relación de sujeción se concibe como la obligada sumisión de los ciudadanos a los poderes públicos, a consecuencia de hallarse en el territorio donde esos poderes ejercen su soberanía; la segunda puede ser conceptuada, por su parte, como aquella sumisión más intensa del particular que la debida a su condición normal de ciudadano, sobre la base de una integración específica en la esfera pública ${ }^{4}$.

\section{La regulación legal y los pronunciamientos jurisprudenciales.}

En la legislación peruana, la concurrencia de pena y sanción administrativa por la realización de un mismo hecho por un mismo sujeto es regulada bajo el ámbito de aplicación del principio del ne bis in ídem en el artículo III del Título Preliminar del Código Procesal Penal. En este dispositivo legal se establece, como regla general, que la pena debe desplazar a la sanción administrativa en su aplicación. En la misma línea, la Ley de Procedimiento Administrativo General dispone, en su artículo 230 inciso 10, que no se podrán imponer sucesiva o simultáneamente una pena y una sanción administrativa por el mismo hecho, cuando se aprecie la identidad de sujeto, hecho y fundamento. Lo dispuesto de manera general en los textos legales antes referidos encuentra excepción, sin embargo, en algunas regulaciones administrativas sectoriales que admiten expresamente la posibilidad de imponer conjuntamente penas y sanciones administrativas, como es el caso, por ejemplo, del artículo 190 del Código Tributario 5 .

Por su parte, la jurisprudencia nacional (tanto de los tribunales ordinarios como del propio Tribunal Constitucional), tiende a afirmar una situación de bis in ídem proscrita cuando, junto con la pena, concurre por el mismo hecho una sanción administrativa motivada por la infracción de una relación de sujeción general. En este caso, las decisiones judiciales sostienen que la respuesta jurídica debe limitarse a la sanción penal. Por el contrario, si la sanción administrativa concurrente tiene su origen en la infracción de una relación de sujeción especial, entonces no habrá problema alguno para aplicarla sucesiva o

\footnotetext{
${ }^{4}$ Vid., RAMÍREZ TORRADO, María Lourdes, "Consideraciones a la figura jurídica de las relaciones de sujeción especial en el ámbito español”, Vuniversitas No 118 (enero-junio 2009), pp. 273 y ss.

${ }^{5}$ Vid., con otras referencias legislativas, REÁTEGUI SÁNCHEZ, James, La garantía del “ne bis in idem” en el ordenamiento jurídico-penal, Lima: Jurista Editores, 2006, p. 82.
} 


\section{GARCÍA, Percy. "El principio del ne bis in ídem material en caso de concurrencia de pena y sanción administrativa".}

conjuntamente con la pena. El sustento de esta acumulación de sanciones sería que, en estos supuestos, no se presenta una identidad de fundamento ${ }^{6}$.

El panorama antes descrito resulta abiertamente insatisfactorio. Si se sigue textualmente lo indicado por los dispositivos legales, el ne bis in ídem se tendría que afirmar respecto de toda situación de concurrencia de pena y sanción administrativa (provenga esta última de la infracción de una relación de sujeción general o especial), a no ser que exista una regulación específica que admita la acumulación sin mayor justificación que la voluntad del legislador. Por el contrario, si se tiene en consideración lo indicado por la doctrina jurisprudencial, entonces todo dependerá de que la sanción administrativa concurrente provenga de la infracción de una relación de sujeción general o especial, pues solamente en el primer caso la duplicidad de sanciones está proscrita. Este razonamiento colisiona, sin embargo, con aquellas regulaciones administrativas que admiten la acumulación de sanciones respecto de infracciones administrativas que parten de una relación de sujeción general. Ante este panorama, se hace necesario una formulación del principio del ne bis in ídem que no solamente cuente con una fundamento razonable, sino que resulte también compatible con lo dispuesto por la ley.

\section{Los presupuestos del ne bis in ídem.}

La posición tradicional, que se ha gestado de la mano de la famosa sentencia emitida al respecto por el Tribunal Constitucional Español en la década de los ochenta (STS de 30 de enero de 1981) ${ }^{7}$, es que una situación de bis in ídem prohibida se produce si dos sanciones se imponen a una misma persona por un mismo hecho y con base en un mismo fundamento. En caso de concurrencia de una sanción penal con una administrativa, lo que se discute especialmente es si tiene lugar la llamada identidad de fundamento ${ }^{8}$. Esta

\footnotetext{
${ }^{6}$ A nivel de la Corte Suprema existe la sentencia vinculante R.N. 2090-2005 del 7 de junio de 2006. Pronunciamientos en el mismo sentido ha hecho reiteradamente el Tribunal Constitucional, tal como lo ponen de manifiesto, con mayores referencias, REÁTEGUI SÁNCHEZ, La garantía, cit. nota $\mathrm{n}^{\circ}$ 5, p. 87 y s.; BOYER CARRERA, Janeyri, "Criterios jurisprudenciales del Tribunal Constitucional sobre el principio del non bis in ídem", $R D A$ 11, Círculo de Derecho administrativo, pp. 323 y ss. Se sigue, en este punto, la línea de interpretación inicialmente asumida por el Tribunal Constitucional Español [vid., GARCÍA ALBERO, "Non Bis in Idem" material, cit. nota n 1, p. 56; RAMÍREZ TORRADO, "Consideraciones a la figura", cit. nota $\mathrm{n}^{\circ}$ 4, pp. 283 y ss.; PÉREZ MANZANO, La prohibición constitucional, cit. nota n ${ }^{\circ}$ 2, p. 23 y s.].

${ }^{7}$ Vid., sobre esta sentencia con mayores referencias, GARCÍA ALBERO, "Non Bis in Idem" material, cit. nota $\mathrm{n}^{\circ} 1$, pp. 53 y ss. Esta posición ha sido asumida reiteradamente por el Tribunal Constitucional Peruano como lo pone en evidencia el reportorio de jurisprudencia sobre el tema sistematizado en ÁVALOS RODRÍGUEZ, Constante Carlos; ROBLES BRICEÑO, Merly Elizabeth, Jurisprudencia penal del Tribunal Constitucional, Lima: Gaceta Jurídica, 2006, pp. 297 y ss.

${ }^{8}$ Esta afirmación no le resta importancia a la exigencia de que se trate del mismo hecho y de que se sancione al mismo sujeto para poder hablar de un bis in ídem, pues estos aspectos de la triple identidad son igualmente necesarios y pueden dar pie, a su vez, a discusiones de especial relevancia como la utilización de un concepto natural o normativo de hecho [vid., MAÑALICH RAFFO, "El principio del ne bis in ídem en el Derecho", cit. nota $\mathrm{n}^{\circ} 2$, pp. 148 y ss.] o la identidad de sujeto en caso de sanciones administrativas aplicables a personas jurídicas [vid., RAMÍREZ TORRADO, María Lourdes, "Consideraciones al requisito de identidad subjetiva del principio del non bis in ídem en el ámbito del Derecho administrativo sancionador español", Revista de Derecho, Vol. XXII, $N^{\circ} 1$ (julio 2009), pp. 93 y ss.]. Lo que aquí se sostiene es que la discusión suele centrarse en la llamada identidad de fundamento porque se trata de sanciones que proceden de ordenamientos sancionatorios distintos.
} 
Polít. crim. Vol. 11, № 21 (Julio 2016), Art. 2, pp. 21-33.

[http://www.politicacriminal.cl/Vol_11/n_21/Vol11N21A2.pdf]

discusión obliga a analizar aquello que sustenta la imposición de cada una de las sanciones concurrentes, esto es, el delito en el caso de la pena y la infracción administrativa respecto de la sanción administrativa.

De lo anterior, queda claro que la premisa conceptual básica para poder encontrar el sentido del ne bis in ídem material en caso de concurrencia de pena y sanción administrativa es determinar si el delito y la infracción administrativa presentan diferencias sustanciales o no. Aunque un sector de la doctrina penal considera que esta discusión es irrelevante para el estudio de la prohibición de la doble sanción, ${ }^{9}$ lo cierto es que todo lo que se pueda decir al respecto presupone, de manera explícita o implícita, una toma de posición sobre la distinción entre delito e infracción administrativa. No hay forma de determinar si la imposición conjunta de pena e infracción administrativa constituye una sobrerreacción sancionatoria, si no se tiene claro la relación funcional entre el Derecho penal y el Derecho administrativo sancionador.

La tesis mayoritaria sostiene que, entre el delito y la infracción administrativa, solamente existe una distinción cuantitativa ${ }^{10}$. Con independencia de los distintos matices que se han formulado al respecto, la idea central es que ambos tipos de injusto están constituidos por la lesión de un bien jurídico, radicando la diferencia únicamente en la mayor gravedad de la lesión que da lugar al delito ${ }^{11}$. Sobre la base de esta identidad esencial de los injustos, se llega lógicamente a la conclusión de que la pena y la sanción administrativa apuntan finalmente a lo mismo: prevenir la futura lesión de bienes jurídicos ${ }^{12}$. Por lo tanto, la imposición de tanto una como otra reacción sancionatoria, responden a un mismo fundamento (la llamada identidad de fundamento).

Si se sigue el planteamiento cuantitativo en el análisis del principio del ne bis in ídem, entonces se podrá decir que siempre que, por un mismo hecho lesivo de un bien jurídico ${ }^{13}$, se le imponga a un mismo sujeto una pena y una sanción administrativa, habrá una identidad de fundamento, pues lo que fundamenta la imposición de la sanción administrativa se encontrará englobado por aquello que fundamenta la pena ${ }^{14}$. Bajo este

\footnotetext{
${ }^{9}$ Vid., así, MAÑALICH RAFFO, "El principio Ne bis in ídem frente a la superposición”, cit. nota $\mathrm{n}^{\circ} 2$, pp. 544 y ss.

${ }^{10}$ Así, ROXIN, Claus, Derecho Penal, Parte General, Madrid: Civitas, 1997, § 2, n.m. 41; CEREZO MIR, José, "Límites entre el Derecho penal y Derecho administrativo", ADPCP 1975, p. 159: "Desde el núcleo del Derecho penal, hasta las últimas faltas penales o administrativas discurre una línea continua de un ilícito material que se va atenuando, pero que nunca llega a desaparecer".

${ }^{11}$ Un sector radical llega a afirmar incluso que la diferencia n siquiera es cuantitativa, sino meramente formal, es decir, según se decida si la impone un juez o la Administración (así, HURTADO POZO, JosÉ; PRADO SALDARRIAGA, Víctor, Manual de Derecho Penal, Parte General, I, 4ª ed., Lima: Idemsa, 2011, § 1, n.m. 122; BAJO FERNÁNDEZ, Miguel, "Nuevas tendencias en la concepción sustancial del injusto penal”, InDret 3/2008, p. 2).

${ }^{12}$ Así discurre el razonamiento de CANO CAMPOS, Tomás, "Non bis in ídem, prevalencia de la vía penal y teoría de los concursos en el Derecho administrativo sancionador", Revista de Administración Pública, № 156 (septiembre-diciembre de 2001), pp. 204 y ss.

${ }^{13}$ PÉREZ MANZANO, La prohibición constitucional, cit. nota $\mathrm{n}^{\circ}$ 2, pp. 118 y ss., hace la precisión de que, para afirmar la identidad de fundamento, no basta una función común de protección de bienes jurídicos en abstracto, sino que es necesario que se trate del mismo bien jurídico concretamente protegido.

${ }^{14}$ Vid., así, REÁTEGUI SÁNCHEZ, La garantía, cit. nota ${ }^{\circ} 5$, pp. 89 y ss.
} 
GARCÍA, Percy. "El principio del ne bis in ídem material en caso de concurrencia de pena y sanción administrativa".

esquema de interpretación, la sanción administrativa no podrá concurrir válidamente con la pena, a no ser que se sustente en un hecho distinto o recaiga sobre un sujeto distinto. El mayor problema de este razonamiento es que no se concilia con la legislación nacional que admite, en ciertas regulaciones administrativas sectoriales, la posibilidad de aplicar conjuntamente pena y sanción administrativa. Del mismo modo, los desarrollos jurisprudenciales tampoco se acomodarán con lo que se deriva de este planteamiento, pues la sanción penal deberá desplazar también a las sanciones disciplinarias.

La tesis minoritaria de la diferencia cualitativa entre el delito y la infracción administrativa conduce, por su parte, a la conclusión contraria. Para esta tesis, el injusto del delito responde a la lesión de un bien jurídico, mientras que la infracción administrativa centra su desvalor en otros aspectos como la falta de obediencia a la relación de dependencia con la autoridad estatal ${ }^{15}$ o la afectación al funcionamiento global de sectores sociales como el sistema financiero, el sistema crediticio, la administración pública, etc. ${ }^{16}$. Por lo tanto, mientras que la pena apunta a prevenir la lesión de bienes jurídicos, lo que la sanción administrativa procura es asegurar el adecuado funcionamiento de los sectores sociales sometidos a regulación. Esta diferencia de fundamento explicaría los distintos criterios de imputación que se manejan en el ámbito penal en relación con los propios del Derecho administrativo sancionador.

Bajo el prisma de carácter cualitativista, el fundamento de la pena será siempre distinto al fundamento de la infracción administrativa concurrente, por lo que no se presentarán las condiciones para afirmar una situación de bis in ídem ${ }^{17}$. Aunque el hecho y el sujeto sean los mismos, el fundamento de cada sanción no lo será, lo que lleva finalmente a que no tenga lugar la llamada triple identidad, necesaria para poder activar la prohibición de la doble sanción. De seguirse este razonamiento, el principio del ne bis in ídem quedará vacío de contenido en todos los casos en los que por un mismo hecho concurran una pena y una sanción administrativa.

La necesidad de atemperar las insatisfactorias consecuencias a las que se llega con los planteamientos antes esbozados, ha llevado a que en la doctrina penal se propongan tesis mixtas. Así, unos parten de que la distinción entre delito e infracción administrativa es puramente cuantitativa, pero aceptan que el Derecho disciplinario, a diferencia del Derecho administrativo sancionador, es sustancialmente distinto al Derecho Penal, por lo que la diferencia entre un delito y una inconducta funcional será de carácter cualitativo ${ }^{18}$. Este intento de rectificación genera, sin embargo, una distorsión insalvable, pues si se parte de

\footnotetext{
15 Vid., GOLDSCHMIDT, James, Das Verwaltungsstrafrecht, Berlin: C. Heymann, 1902, pp. 539 y ss. Anteriormente BINDING, Karl, Die Normen und ihre Übertretung, I, Leipzig, Engelmann, 1922, pp. 397 y ss., catalogó el delito administrativo como simple desobediencia.

${ }^{16}$ Vid., SILVA SÁNCHEZ, José María, La expansión del Derecho penal, Madrid: JM Bosch, 2001, p. 126; GARCÍA CAVERO, Percy, Derecho penal económico, Parte General, $3^{a}$ ed., Lima: Jurista Editores, 2014, p.141 y s.

${ }^{17}$ Vid., NIETO, Alejandro, Derecho administrativo sancionador, 4ª ed., Madrid: Tecnos, 2005, p. 474.

${ }^{18}$ Vid., en esta línea, QUINTERO OLIVARES, Gonzalo, "La autotutela, los límites al poder sancionador de la Administración pública y los principios inspiradores del Derecho penal", Revista de Administración Pública, No 126 (1991), p. 285 y s.; NIETO, Derecho administrativo sancionador, cit. nota n ${ }^{\circ} 17$, p. 505.
} 
Polít. crim. Vol. 11, № 21 (Julio 2016), Art. 2, pp. 21-33.

[http://www.politicacriminal.cl/Vol_11/n_21/Vol11N21A2.pdf]

que el Derecho disciplinario es abarcado por el Derecho administrativo sancionador ${ }^{19}$, no es coherente decir luego que dicho ámbito cuenta con un fundamento cualitativamente distinto al Derecho penal. Por esta razón, algunos autores han optado por sustentar la posibilidad de una doble sanción no en la simple existencia de una relación de sujeción especial, pues el fundamento de la pena y la sanción disciplinar sigue siendo el mismo, sino en que la sanción penal no presuponga la infracción de deberes funcionariales. En consecuencia, en los delitos de funcionario público no se podrá imponer una sanción penal y disciplinar, mientras que si se trata de un delito común cometido por un funcionario público, no habrá identidad de fundamento entre las sanciones concurrentes ${ }^{20}$.

\section{El fundamento del ne bis in ídem a partir de la distinción cualitativa entre delito e infracción administrativa.}

Como se dijo anteriormente, no es posible dimensionar el principio de non bis in ídem material por concurrencia de pena y sanción administrativa sin tomar partido por alguna de las tesis de diferenciación entre el delito y la infracción administrativa, pues resulta imprescindible determinar si el fundamento de la pena es el mismo que el fundamento de la sanción administrativa concurrente. En este orden de ideas, considero que lo que media entre ambos injustos es una diferencia de carácter cualitativo ${ }^{21}$, lo que conlleva indefectiblemente fundamentos distintos en su imposición. Esto no significa, sin embargo, que nunca se presentará una situación de bis in ídem si es que, por un mismo hecho, se impone a un mismo sujeto una pena y una sanción administrativa. Si bien el enfoque utilizado por cada orden jurídico es distinto, ambos parten de un hecho fáctico común y sus respuestas jurídicas inciden en una misma realidad, lo que es un dato sumamente relevante como se verá a continuación.

El punto de partida común para ambas clases de sanción es un hecho que defrauda una expectativa social. Frente a la defraudación de una expectativa social, se puede actuar cognitiva (sacándola del esquema de orientación jurídicamente válido) o normativamente (manteniendo su vigencia a pesar de su defraudación fáctica) ${ }^{22}$. El mantenimiento

\footnotetext{
${ }^{19}$ El la doctrina se admite que el Derecho disciplinario forma parte del Derecho administrativo. De una idéntica naturaleza jurídica entre infracción administrativa e infracción disciplinaria habla GÓMEZ TOMILlO, Manuel, Derecho administrativo sancionador, Parte General, Pamplona: Thomson Aranzadi, 2008, p. 201. Sobre el Derecho disciplinario como una vertiente especializada del Derecho administrativo sancionador, VACAS GARCÍA-ALÓS, Luis; MARTÍN MARTÍN, Gervasio, Manual de Derecho Disciplinario Judicial, Pamplona: Thomson Aranzadi, 2005, p. 19. Por su parte, NIETO, Derecho administrativo sancionador, cit. nota $\mathrm{n}^{\circ} 17$, p. 226, se ocupa del Derecho disciplinario en el marco del Derecho administrativo sancionador, aunque reconociendo ciertas particularidades en su configuración. Como parte de un Derecho Sancionador lo clasifica, GÓMEZ PAVAJEAU, Carlos, Dogmática del Derecho Disciplinario, Bogotá: ediciones Universidad del Externado de Colombia, 2007, p. 206.

20 Vid., ampliamente, la exposición que hace HUERTA TOCILDO, Susana, "Ilícito penal e ilícito disciplinario de funcionarios", en: VV. AA., La ciencia del Derecho Penal ante el nuevo siglo, Libro Homenaje al Prof. José Cerezo Mir, Madrid: Tecnos, 2002, pp. 66 y ss.

21 Las razones de esta toma de postura se pueden consultar en GARCÍA CAVERO, Derecho Penal Económico, cit. nota $\mathrm{n}^{\circ} 16$, pp. 138 y ss.

22 Sobre la restabilización cognitiva y la normativa, vid, con mayores referencias, JAKOBS, Günther, Derecho Penal, Parte General, Madrid: Marcial Pons, 1997, Apdo 1, n.m. 4 y ss.: EL MISMO, "Expectativas
} 
GARCÍA, Percy. "El principio del ne bis in ídem material en caso de concurrencia de pena y sanción administrativa".

normativo de la expectativa puede, a su vez, llevarse a cabo con medios cognitivos (tomando medidas eficaces para impedir una nueva defraudación) o con medios normativos (afirmando comunicativamente su validez). Aquí radica, a nuestro entender, la diferencia cualitativa entre la infracción administrativa y el delito. Mientras la primera se determina en un plano cognitivo al tratar al administrado como un ser sensible que debe ser conminado a actuar correctamente en el sector administrativamente regulado, el segundo parte de un ciudadano entendido como un ser inteligible, cuyo comportamiento debe ser merecedor de una pretensión de validez ${ }^{23}$.

Lo anterior pone en evidencia que la sanción administrativa se sustenta en algo cualitativamente distinto a la pena. Administrativamente lo que la sanción procura es generar las condiciones empíricas para que el sector social regulado no colapse. Lo usual es conseguirlo por medio de estímulos negativos externos sobre los administrados que los motiven a observar los estándares de actuación establecidos. Pero también es posible que la sanción administrativa llegue incluso a prescindir de la motivación individual en sectores sociales especialmente complejos y apunte únicamente a hacer una asignación eficiente de los riesgos. Esto explica, entre otras cosas, que el principio de culpabilidad no sea siempre necesario para la imposición de sanciones en el Derecho administrativo sancionador, tal y como se puede corroborar en ámbitos como el ambiental o de protección al consumidor. Al tratarse al administrado en su faceta sensible, no hay nada irrenunciable que obligue a fundamentar la imposición de las sanciones en la motivación individual. En contraposición a lo anterior, la flexibilidad de los criterios para imponer las sanciones administrativas hace evidente por qué las mismas no pueden significar, bajo ningún escenario posible, una privación de la libertad $^{24}$.

La situación es sustancialmente distinta en el caso de la pena. Esta sanción se dirige al condenado como ser racional para negar comunicativamente el sentido social de su actuación delictiva, lo que hace imprescindible la realización de un juicio de culpabilidad por un hecho propio ${ }^{25}$. No hay forma de llevar a cabo la negación comunicativa de la conducta defraudatoria sin el reproche al que da lugar la culpabilidad por el injusto realizado. La pena restablece la vigencia de la expectativa normativa defraudada por el autor como ser inteligible. Esta fundamentación autoriza a que el fracaso organizativo del condenado en su orientación social pueda expresarse mediante la privación de derechos de la libertad tan esenciales como la libertad de movimiento.

La diferencia funcional que se acaba de postular entre el orden penal y el administrativo no implica, sin embargo, una desvinculación de los fundamentos de la pena y la sanción

normativas", en: POLAINO-ORTS, Miguel (Coord.), El lado comunicativo y el lado silencioso del Derecho Penal, Lima: Ediciones del Centro, 2015, pp. 75 y ss.

${ }^{23}$ Desde Kant se ha diferenciado en el hombre dos mundos: el homo phaenomenon y el homo noumenon (KANT, Immanuel, Grundlegung zur Metaphysik der Sitten, Akademie-Ausgabe, IV, Berlin: De Gruyter, 1968, p. 448). El primero es el aspecto sensible de la persona que reacciona ante los estímulos externos del entorno, mientras que el segundo es su caracterización como ser racional dotado de voluntad que actúa bajo la idea de libertad.

${ }^{24}$ GARCÍA CAVERO, Derecho Penal Económico, cit. nota n ${ }^{16}$, p. 141.

${ }^{25}$ Vid., al respecto, JAKOBS, Günther, Sobre la normativización de la dogmática jurídico-penal, Madrid: Thomson Aranzadi - Cuadernos Civitas, 2003, p. 50 y s. 
Polít. crim. Vol. 11, № 21 (Julio 2016), Art. 2, pp. 21-33.

[http://www.politicacriminal.cl/Vol_11/n_21/Vol11N21A2.pdf]

administrativa. Si bien el fundamento de la pena se mueve en el plano de la racionalidad comunicativa, lo cierto es que su imposición despliega, en la realidad, un efecto empírico aflictivo que no puede desconocerse ${ }^{26}$ y que podría llegar a cubrir la finalidad legitimante del Derecho administrativo sancionador. En efecto, si la imposición de la pena por el hecho penalmente relevante trae consigo en el plano empírico las condiciones para la funcionalidad del sector social administrativamente regulado, entonces no será necesario sumar a la pena una sanción administrativa. Hacerlo sería una innecesaria restricción de derechos y, por ello, un bis in ídem, pues la sanción penal ya desplegó a nivel empírico lo que reclama la imposición de la sanción administrativa.

El efecto empírico desplegado por la pena y que hace innecesaria la imposición de la sanción administrativa no puede, sin embargo, tener cualquier procedencia. La identidad de hecho exige una vinculación fáctica entre el delito y la infracción administrativa. Esta vinculación se satisface con la exigencia de que el hecho que se subsume en el tipo penal, se subsuma también en el tipo infraccional. El concepto de hecho no está definido, por lo tanto, en un sentido intensional (propio del concurso de leyes y la prohibición de la doble

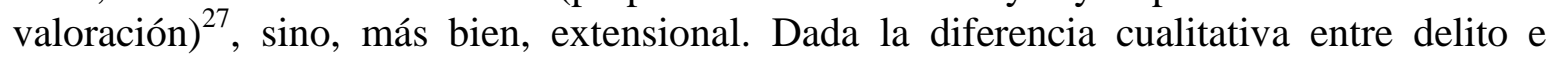
infracción administrativa, no es posible establecer puntos de identidad valorativa a nivel del juicio de tipicidad. La única vinculación entre ambas clases de injusto es un mismo hecho que cumple con el supuesto de hecho de la ley penal y de la ley administrativa.

\section{Consecuencias.}

Con base en lo anterior, puede decirse que el principio del ne bis in ídem material por concurrencia de pena y sanción administrativa es una expresión del juicio de necesidad. Su naturaleza constitucional se lo debe, por lo tanto, no al principio de legalidad ${ }^{28}$, sino al de proporcionalidad $^{29}$. Cabe, sin embargo, hacer la precisión de que este juicio de necesidad no le corresponde hacer al legislador, sino al juez ${ }^{30}$, por lo que no se trata de una cuestión de proporcionalidad abstracta, sino, más bien, concreta. Por lo tanto, no está en manos del legislador decidir por medio de una regulación general si la pena debe imponerse conjuntamente con la sanción administrativa o no, sino que le atañerá al juez hacerlo a través de un juicio de necesidad en el caso concreto. Lo anterior precisa que se instituya la

\footnotetext{
${ }^{26}$ E incluso resulta necesario como lo pone de manifiesto JAKOBS, Günther, El fundamento del sistema penal, Lima, 2005, pp. 43 y ss.

27 A diferencia del razonamiento de MAÑALCH RAFFO, "El principio Ne bis in ídem frente a la superposición”, cit. nota ${ }^{\circ}$ 2, pp. 551, 558 ó PÉREZ MANZANO, La prohibición constitucional, cit. nota ${ }^{\circ}$ 2, pp. 100 y ss., que llevan a un concepto intencional de hecho.

${ }^{28}$ Como lo sostiene, por el contrario, la jurisprudencia constitucional española, como lo informa GARCÍA ALBERO, "Non Bis in Idem” material, cit. nota $\mathrm{n}^{\circ} 1$, pp. 75 y ss.

${ }^{29}$ Igualmente, CANO CAMPOS, "Non bis in ídem", cit. nota n' 12, p. 203; QUINTERO OLIVARES, "La autotutela", cit. nota $\mathrm{n}^{\circ} 18$, p. 281; MAÑALICH RAFFO, "El principio Ne bis in ídem frente a la superposición”, cit. nota ${ }^{\circ} 2$, p. 548, aunque referido a la prohibición de exceso.

${ }^{30}$ Resalta que el principio del ne bis in ídem como estándar de adjudicación es vinculante para el adjudicador, mas no, al menos directamente, para el legislador, MAÑALICH RAFFO, "El principio del ne bis in ídem en el Derecho", cit. nota ${ }^{\circ} 2$, p. 143. Igualmente, NIETO, Derecho administrativo sancionador, cit. nota $\mathrm{n}^{\circ} 17$, p. 477.
} 
GARCÍA, Percy. "El principio del ne bis in ídem material en caso de concurrencia de pena y sanción administrativa".

práctica judicial de determinar en la sentencia penal condenatoria si procede imponerle al autor además una sanción administrativa por la autoridad administrativa correspondiente ${ }^{31}$.

Bajo las consideraciones precedentes, el artículo III del Título Preliminar del Código Procesal Penal solamente es aplicable en los casos en los que se pueda afirmar las condiciones de un bis in ídem. Sin entrar en la identidad de hecho y sujeto que no han sido abordados con detalle en el presente trabajo, queda claro que la identidad de fundamento debe ser reformulada para ser entendida, más bien, como una identidad de efecto. Esta expresión significa que si la imposición de la pena despliega empíricamente efectos que cubren la finalidad legitimante de la sanción administrativa, entonces no será necesario imponer acumulativamente esta última. Solamente si la pena no cubriese con su imposición lo que fundamenta, en el plano empírico, la aplicación de una sanción administrativa, entonces la imposición conjunta se encontrará justificada. Por lo expuesto, el principio de "no dos veces sobre lo mismo" en caso de concurrencia de pena y sanción administrativa no debe entenderse como prohibición de una doble valoración del hecho con fines sancionatorios, sino como prohibición de sancionar aquello que ya está, en los hechos, sancionado.

Por su parte, las regulaciones administrativas sectoriales que admiten la posibilidad de aplicar conjuntamente una pena y una sanción administrativa, no deben ser entendidas como excepciones al principio del ne bis in ídem, sino como el reconocimiento expreso de que la imposición de una pena no impide que se pueda imponer por el mismo hecho una sanción administrativa, si es que la pena no ha desplegado los efectos empíricos que satisfacen el fin de protección de la norma administrativa sancionatoria. Entre la regulación general y la especial de una situación de concurrencia de pena y sanción administrativa no hay una relación de regla-excepción, sino, más bien, una correcta delimitación de los supuestos en los que la concurrencia está proscrita y en los que no lo está.

Pese a que, tal como lo dijimos, la determinación de la necesidad de sanción es una cuestión que solamente puede llegar a determinarse en el caso concreto, eso no impide que se puedan establecer ciertas pautas generales. En principio, la pena cubre empíricamente el fundamento de la sanción administrativa derivada de la infracción de una relación de sujeción general. Esto, sin embargo, no se presentará si la pena no despliega el efecto empírico de asegurar cognitivamente la observancia de los estándares de actuación en el sector social administrativamente regulado. Tal situación tendrá lugar a todas luces, por ejemplo, cuando el juez suspende condicionalmente la ejecución de la pena o cuando reserva el fallo condenatorio. Por el contrario, la pena no cubre, por lo general, el fundamento de las sanciones disciplinarias que procuran la exclusión del sujeto sometido a una relación de sujeción especial ${ }^{32}$, por lo que su imposición no tendrá por qué impedir la destitución del funcionario público, por ejemplo.

\footnotetext{
${ }^{31}$ Así, lo recomienda también QUINTERO OLIVARES, "La autotutela", cit. nota $\mathrm{n}^{\circ} 18$, p. 284, por exigencias de autotutela y seguridad jurídica.

${ }^{32}$ Así, NIETO, Derecho administrativo sancionador, cit. nota ${ }^{\circ} 17$, pp. 226 y ss., sostiene que las sanciones disciplinarias no son expresión de la potestad sancionatoria, sino de la capacidad propia de autorregulación de la Administración Pública.
} 
Polít. crim. Vol. 11, No 21 (Julio 2016), Art. 2, pp. 21-33.

[http://www.politicacriminal.cl/Vol_11/n_21/Vol11N21A2.pdf]

Como cuestión final, cabe señalar que al centrar el sentido y alcance del supuesto de ne bis in ídem aquí estudiado en el criterio de la necesidad de sanción, no se establece una predominancia absoluta de la sanción penal sobre la sanción administrativa ${ }^{33}$. Dado que la sanción administrativa no se mueve en el plano comunicativo que precisa la respuesta a un delito, la regla será que la pena desplace la imposición de la sanción administrativa, tal como lo señala el artículo III del Título Preliminar del Código Procesal Penal. Sin embargo, esta regla puede encontrar una excepción si el injusto penal realizado es especialmente débil y la sanción administrativa prevista sumamente intensa ${ }^{34}$. En este caso, la intensidad empírica de la sanción administrativa podrá cubrir la poca cuota comunicativa de la pena y, por lo tanto, hacer a esta última innecesaria. Tal situación se presenta, por ejemplo, en el caso de tentativa por un delito de peligro concreto que constituye, a la vez, una infracción administrativa sancionada con multas millonarias. Aquí, la relación de necesidad se invierte, por lo que bastará con imponer la sanción administrativa especialmente intensa.

\footnotetext{
${ }^{33}$ De distinto parecer, CANO CAMPOS, "Non bis in ídem”, cit. nota n 12 , pp. 214 y ss.

34 Igualmente reconoce que puede establecerse excepciones a la regla de la supremacía de la ley penal, PÉREZ MANZANO, La prohibición constitucional, cit. nota $\mathrm{n}^{\circ} 2$, p. 63 y s.
} 
GARCÍA, Percy. "El principio del ne bis in ídem material en caso de concurrencia de pena y sanción administrativa".

\section{BIBLIOGRAFÍA}

BAJO FERNÁNDEZ, Miguel, "Nuevas tendencias en la concepción sustancial del injusto penal", InDret 3/2008, pp. 1 y ss.

BAJO, Miguel; BACIGALUPO, Miguel, "Las medidas administrativas y penales de prevención del blanqueo de capitales en el ámbito urbanístico: Límites entre las infracciones administrativas y delito", ADFUAM 12 (2008), pp. 15 y ss.

BINDING, Karl, Die Normen und ihre Übertretung, I, Leipzig: Engelmann, 1922.

BOYER CARRERA, Janeyri, "Criterios jurisprudenciales del Tribunal Constitucional sobre el principio del non bis in ídem”, RDA 11, Círculo de Derecho administrativo, pp. 323 y ss.

CANO CAMPOS, Tomás, "Non bis in ídem, prevalencia de la vía penal y teoría de los concursos en el Derecho administrativo sancionador", Revista de Administración Pública, No 156 (septiembre-diciembre de 2001), pp. 191 y ss.

CEREZO MIR, José, "Límites entre el Derecho penal y Derecho administrativo", ADPCP 1975 , p. 171 y ss.

GARCÍA ALBERO, Ramón, "Non Bis in Ídem” material y concurso de leyes penales, Barcelona: Cedes Editorial S.L., 1995.

GARCÍA CAVERO, Percy, Derecho penal económico, Parte General, $3^{\mathrm{a}}$ ed., Lima: Jurista Editores, 2014.

GOLDSCHMIDT, James, Das Verwaltungsstrafrecht. Eine Untersuchung der Grenzgebiete zwischen Strafrecht und Verwaltungsrecht auf rechtsgeschichtlicher und rechtsvergleichender Grundlage, Berlin: C. Heymann, 1902.

GÓMEZ PAVAJEAU, Carlos, Dogmática del Derecho Disciplinario, $4^{\mathrm{a}}$ Ed., Bogotá: ediciones Universidad del Externado de Colombia, 2007.

GÓMEZ TOMILLO, Manuel, Derecho administrativo sancionador, Parte General, Pamplona: Thomson Aranzadi, 2008.

HUERTA TOCILDO, Susana, "Ilícito penal e ilícito disciplinario de funcionarios", en: VV. AA., La ciencia del Derecho Penal ante el nuevo siglo, Libro Homenaje al Prof. José Cerezo Mir, Madrid: Tecnos, 2002, pp. 37 y ss.

HURTADO POZO José; PRADO SALDARRIAGA, Víctor, Manual de Derecho Penal, Parte General, I, $4^{\mathrm{a}}$ ed., Lima: Idemsa, 2011.

JAKOBS, Günther, "Expectativas normativas", en: POLAINO-ORTS, Miguel, (Coord.) El lado comunicativo y el lado silencioso del Derecho Penal, Lima: Ediciones del Centro, 2015. , Derecho Penal, Parte General, Madrid: Marcial Pons, 1997. , El fundamento del sistema penal, Lima: Ara Editores, 2005.

, Sobre la normativización de la dogmática jurídico-penal, Madrid: Thomson Aranzadi - Cuadernos Civitas, 2003.

KANT, Immanuel, Grundlegung zur Metaphysik der Sitten, Akademie-Ausgabe, IV, Berlin: De Gruyter, 1968.

MAÑALICH RAFFO, Juan Pablo, "El principio del ne bis in ídem en el Derecho penal chileno", Revista de Estudios de la Justicia, $\mathrm{N}^{\circ} 15$ (2011), pp. 139 y ss.

, "El principio Ne bis in ídem frente a la superposición del derecho penal y el derecho administrativo sancionatorio", Polít. crim. Vol. 9, $\mathrm{N}^{\circ} 18$ (diciembre de 2014), pp. 543 y ss. 
Polít. crim. Vol. 11, No 21 (Julio 2016), Art. 2, pp. 21-33.

[http://www.politicacriminal.cl/Vol_11/n_21/Vol11N21A2.pdf]

NIETO, Alejandro, Derecho administrativo sancionador, $4^{\mathrm{a}}$ ed., Madrid: Tecnos, 2005.

PÉREZ MANZANO, Mercedes, La prohibición constitucional de incurrir en bis in ídem, Valencia: Tirant lo Blanch, 2002.

QUINTERO OLIVARES, Gonzalo, "La autotutela, los límites al poder sancionador de la Administración pública y los principios inspiradores del Derecho penal”, Revista de Administración Pública, № 126 (1991), pp. 253 y ss.

RAMÍREZ TORRADO, María Lourdes, "Consideraciones a la figura jurídica de las relaciones de sujeción especial en el ámbito español”, Vuniversitas $\mathrm{N}^{\circ} 118$ (enerojunio 2009), pp. 273 y ss.

, "Consideraciones al requisito de identidad subjetiva del principio del non bis in ídem en el ámbito del Derecho administrativo sancionador español”, Revista de Derecho, Vol. XXII, Nº 1 (julio 2009), pp. 93 y ss.

REÁTEGUI SÁNCHEZ, James, La garantía del "ne bis in idem" en el ordenamiento jurídico-penal, Lima: Jurista Editories, 2006.

ROXIN, Claus, Derecho Penal, Parte General, Madrid: Civitas, 1997.

SILVA SÁNCHEZ, José María, La expansión del Derecho penal, Madrid: JM Bosch, 2001.

VACAS GARCÍA-ALÓS, Luis; MARTÍN MARTÍN, Gervasio, Manual de Derecho Disciplinario Judicial, Pamplona: Thomson Aranzadi, 2005.

VERVAELE, John, "Ne bis in ídem: ¿un principio transnacional de rango constitucional en la Unión Europea?”, InDret 1/2014, pp. 1 y ss. 